Original article (short paper)

\title{
The motor deficits caused by Parkinson's disease are not able to block adjustments for a safe strategy during obstacle crossing in individuals with moderate disease
}

\author{
Vinícius Alota Ignácio Pereira \\ Universidade Estadual Paulista, Rio Claro, Brazil \\ Fabio Augusto Barbieri \\ Universidade Estadual Paulista, Bauru, Brazil \\ Rodrigo Vitório \\ Lucas Simieli \\ Ellen Lirani-Silva \\ Diego Orcioli-Silva \\ Lilian Teresa Bucken Gobbi \\ Universidade Estadual Paulista, Rio Claro, Brazil
}

\begin{abstract}
The aim of this study was to verify whether patients with Parkinson's disease (PD) are able to adjust their motor behavior according to restrictions imposed by the task instruction during walking with obstacle crossing. Eighteen elderly people (moderate motor compromise) with a diagnosis of PD walked on a pathway and cross an obstacle according to the following conditions: walking at preferred velocity; walking at maximum vertical elevation of the feet to cross the obstacle; walking at maximum step length to cross the obstacle; walking at maximum velocity. The modulations were directly related to the instructions provided to patients with PD before performing each task, which seems to indicate that attentional cues can influence and benefit strategies during obstacle crossing. In conclusion, patients with PD are able to adjust walking during obstacle crossing according to instructions given to them, which increases their safety.
\end{abstract}

Keywords: Parkinson's disease, gait, movement, time and motion studies, spatial behavior

Resumo - “O déficit motor causado pela doença de Parkinson não é capaz de bloquear os ajustes para uma estratégia segura durante a travessia de obstáculos em indivíduos com doença moderada.” O objetivo deste estudo foi verificar se pacientes com doença de Parkinson (DP) são capazes de modular o comportamento motor de acordo com restrições impostas pela instrução na tarefa de ultrapassagem de obstáculo. Dezoito idosos com diagnóstico de DP (comprometimento motor moderado) andaram sobre uma passarela e ultrapassaram um obstáculo de acordo com as seguintes instruções: velocidade preferida; elevação máxima do pé para ultrapassagem do obstáculo; máximo comprimento do passo de ultrapassagem; ultrapassagem em máxima velocidade. As modulações realizadas estão diretamente relacionadas às instruções dadas aos pacientes antes da realização de cada tarefa, o que indica que dicas auditivas podem influenciar e beneficiar as estratégias utilizadas. Através deste estudo é possível concluir que pacientes com DP são capazes de modular a ultrapassagem de obstáculo de acordo com a instrução que lhes é dada, o que aumenta a segurança na tarefa.

Palavras-chave: doença de Parkinson, marcha, movimento, estudos de tempo e movimento comportamento espacial

Resumen - “El déficit motor causados por la enfermedad de Parkinson no es capaces de bloquear los ajustes para una estrategia de seguridad durante la travesía del obstáculo en individuos con enfermedad moderada." El objetivo de este estudio fue verificar se los pacientes con enfermedad de Parkinson (EP) son capaces de modular el comportamiento motor de acuerdo con restricciones impuestas por la instrucción en la tarea de sobrepasar un obstáculo. Dieciocho adultos mayores con diagnóstico de EP (con deficiencia motora moderada) caminaran sobre una pasarela e sobrepasaran un obstáculo de acuerdo con las siguientes instrucciones: velocidad preferida; elevación máxima del pie para sobrepasar el obstáculo, máxima distancia del paso para sobrepasar el obstáculo; sobre pasada máxima velocidad. Las modulaciones realizadas están directamente relacionadas a las instrucciones dadas a los pacientes antes de la realización de cada tarea, lo que indica que pautas auditivas pueden influenciar e beneficiar las estrategias utilizadas. A través de este estudio se puede concluir que pacientes con EP son capaces de modular la sobrepasada de obstáculo de acuerdo con la instrucción que les es dada, lo que aumenta la seguridad en la tarea.

Palabras claves: enfermedad de parkinson, marcha, movimiento, estudios de tiempo y movimiento, conducta espacial 


\section{Introduction}

Parkinson's disease (PD) is the second most common neurodegenerative disorder in the elderly and affects approximately $3.3 \%$ of the elderly in Brazil (Barbosa et al., 2006). Patients with PD demonstrate some signals and motors symptoms, such as hypometria (reduced range of motion), bradykinesia (slowness of movement execution) and muscle stiffness of the lower limbs, which influence daily activities, predominantly walking (Dias, Fraga, Cacho, \& Oberg, 2005; Fernández-del Olmo, Arias, \& Cudeiro, 2004; Goulart, Santos, Teixeira-Salmela, \& Cardos, 2004; Morris \& Iansek, 1996; Reisis, 2004; Teixeira $\&$ Alouche, 2007). Recent research has confirmed the effects of motor symptoms on the gait of patients with $\mathrm{PD}$, primarily during obstacle crossing (Adkin, Bloem, \& Allum, 2005; Galna, Murphy, \& Morris, 2010; Latt, Menz, Fung, \& Lord, 2009; Pieruccini-Faria et al., 2006; Stegemöller, 2012; Vitório, Pieruccini-Faria, Stella, Gobbi, \& Gobbi, 2010). The gait of this population is characterized by reduced velocity, shortened step length and larger step width (Galna et al., 2010; Pieruccini-Faria et al., 2006; Stegemöller, 2012; Vitório et al., 2010), which is a more conservative strategy during obstacle crossing than in healthy individuals (Galna et al., 2010; Pieruccini-Faria et al., 2006; Stegemöller, 2012). Despite this conservative strategy, tripping during obstacle crossing is one of the major causes of falls in this population (Stolze et al., 2004), representing 60\% of falls (Balash et al., 2005).

To avoid contact with the obstacle and improve safety during walking with obstacle crossing, adjustments to walking parameters are necessary. The literature indicates that increases in stride length, walking speed, foot placement before the obstacle and toe-clearance are the main strategies for avoiding foot-obstacle contact during obstacle crossing (Chou \& Draganich, 1998; Pieruccini-Faria et al., 2006; Vitório et al., 2010). These safety strategies are directly associated with the motor signals/ symptoms of PD: i) Hypometria of the horizontal and vertical trajectory of the foot during obstacle crossing, which is related to stride length, foot placement before the obstacle and toe-clearance, increases the risk of tripping (Galna et al., 2010); ii) Bradykinesia, which is related to walking speed, increases postural instability during walking since the individuals spend more time on a single support due to slowness during obstacle crossing, which is the most unstable phase of walking (Vitório, 2014a). Therefore, as a result of the motor limitations caused by the disease, patients with PD have impairments in their ability to perform adjustments when walking to safely cross obstacles (Galna et al., 2010). However, patients with PD seem to be able to walk with more safety when external cues are provided (Picelli, 2010; Spaulding, 2013).

In this context, it is important to understand the strategies used by patients with PD during walking with obstacle crossing after an instruction to perform the task and, also, whether they are able to overcome the motor impairment of the disease during the task. Findings in this context may aid the design of intervention programs aiming to reduce the occurrence of falls in patients with PD. Therefore, the aim of this study was to verify whether patients with PD are able to adjust their motor behavior according to restrictions imposed by the task instructions during walking with obstacle crossing. We hypothesized that patients with PD would be able to adjust their motor behavior according to task instructions during obstacle crossing. The hypothesis was supported by past studies, which suggest that patients with PD are able to modulate gait in accordance with environmental restrictions (Vitório et al., 2010), auditory cues (Picelli, 2010; Spaulding, 2013) and visual cues (Azulay et al., 1999; Morris \& Iansek, 1996; Morris, Iansek, Matyas, \& Summers, 2005). Focusing on the instruction could favor a change from automatic movement control (subcortical) to directed control with a goal (cortical). In this way, the cortex would assume the main role, reducing the actions of neural circuits compromised by DP (Beeler, Petzinger, \& Jakowec, 2013; Petzinger et al., 2013; Redgrave et al., 2010).

\section{Method}

All the procedures were realized in Posture and Gait Studies Lab (LEPLO), in São Paulo State University (UNESP) at Rio Claro, Institute of Biosciences, Department of Physical Education. Eighteen elderly individuals with idiopathic PD (ten women and eight men), between stages I and III on the Hoehn \& Yahr rating scale (H\&Y; Hoehn \& Yahr, 1967), participated in this study (Table 1). We selected the participants from the Physical Activity Program for Patients with PD (PROPARKI Group - UNESP - Rio Claro - Brazil) database (more than one hundred individuals), which has been developed in operation since 2004. The patients were required to be able to walk independently (walking without devices, such as cane, crutch or walkers, or helping another person), and regularly use PD medication. Exclusion criteria were musculoskeletal, orthopedic, or neurological disorders other than PD that affect walking. Just participants who fit themselves to the inclusion criteria, and have no exclusion criteria, were recruited for this study. All participants signed a consent form, submitted to and approved by the local Ethics Committee (\#4891/2012).

Table 1. Means and standard deviations of characteristics of patients with PD. UPDRS III: motor component of the Unified Parkinson's Disease Rating Scale; MMSE: Mini-Mental State Examination; H\&Y: Hoehn\&Yahr.

\begin{tabular}{cccccc}
\hline Age (years) & Body weight $(\mathbf{k g})$ & Body height $(\mathbf{m})$ & UPDRS-III (pts) & MMSE (pts) & H\&Y (pts) \\
\hline $68.00 \pm 6.05$ & $65.10 \pm 7.70$ & $1.60 \pm .10$ & $26.00 \pm 12.22$ & $27.00 \pm 2.63$ & $1.70 \pm .73$ \\
\hline
\end{tabular}


All the procedures were realized in ON medications state. Initially, the patients with PD answered a full anamnesis including disease injuries and current medication, in addition to other information relevant to verify the inclusion criteria, during the anamnesis we identified all patients were right-footed. This procedure was performed accompanied by the caregiver of the patients. Subsequently, patients were evaluated through the H\&Y scale, the motor component of the Unified Parkinson's Disease Rating Scale (Fahn \& Elton, 1987) and the Mini-Mental State Examination (Folstein, Folstein, \& McHugh, 1975).

For the experimental tasks, the patients were instructed to walk on a pathway ( $8 \mathrm{~m}$ long by $1.4 \mathrm{~m}$ wide), step overran obstacle, and keep walking until the end of the pathway. The patients were instructed to avoid contact with the obstacle, which was positioned in the middle of the pathway. The starting position was modified for each patient to ensure a comfortable crossing with the dominant limb (nearly $4 \mathrm{~m}$ from the starting point). The obstacle height was adjusted to half the knee height (from 20 to $25 \mathrm{~cm}$ ) for each patient. The obstacle (width=50 $\mathrm{cm}$; depth $=2 \mathrm{~cm}$ ) was made of wood and was collapsible when contacted for safety. The participants were evaluated in $\mathrm{ON}$ (optimal) medication state.

Four experimental conditions were performed:

a) Preferred velocity to cross the obstacle: The participants were instructed to walk at a self-selected velocity and step length when crossing the obstacle;

b) Maximum elevation of the feet to cross the obstacle: The participants were instructed to walk at a self-selected velocity and step length and to increase their feet-obstacle vertical distance (foot clearance) as much as possible when crossing the obstacle;

c) Maximum step length to cross the obstacle: The participants were instructed to walk at a self-selected velocity and perform maximum step length when crossing the obstacle;

d) Maximum velocity to cross the obstacle: The participants were instructed to walk and cross the obstacle at the highest walking velocity possible without running.
Each participant performed, in blocks, three trials in each condition. Initially, each participant performed the preferred velocity condition. The other experimental conditions were randomized between the participants by drawing lots.

For the spatial-temporal parameters, a digital camera (Samsung, model SC-D364) was positioned in the sagittal right plane of the participant to view all markers. Four passive markers (15-mm diameter) were attached to the following anatomical landmarks: (a) 5th right and 1st left metatarsal joints and (b) lateral face of the right calcaneus and medial face of the left calcaneus. One passive marker was also fixed at the obstacle top for calculation of the dependent variables related to obstacle distance.

The images were recorded at $60 \mathrm{~Hz}$ and captured using a video card (Pinnacle, model Studio DV, version 1.05.307) coupled to a microcomputer and compressed using a logarithmic compression (Ligos Indeo 5.10). For better reflection and visualization of the markers two spotlights with halogen lamps of $500 \mathrm{~W}$ were positioned to the side of the camera. The calibration of the two-dimensional experimental set was performed through plumb lines with markers with known distances between them ( $3 \mathrm{~m} \mathrm{X} 1.7 \mathrm{~m})$. The markers were digitized automatically on Digital Video for Windows software $\left(\right.$ Dvideow $\left.{ }^{\circledR}\right)$. The Matlab $^{\circledR}$ (The Math Works, Natick, MA, USA, version 6.5) algorithm was used to calculate the dependent variables. The data were filtered with a fifth-order Butterworth low-pass filter with a cutoff frequency of $6 \mathrm{~Hz}$.

The cycle analyzed was the obstacle crossing stride (Figure 1). In each trial, stride length, stride duration, stride velocity and double support duration (percentage of stride duration) were measured. In addition; the toe clearance of the leading and trailing limbs (vertical distance from foot to obstacle); the horizontal distance from the leading limb to the obstacle before and after obstacle crossing and the horizontal distance from trailing limb to the obstacle before obstacle crossing were measured. Furthermore, we quantified the number of contacts with the obstacle for each condition.

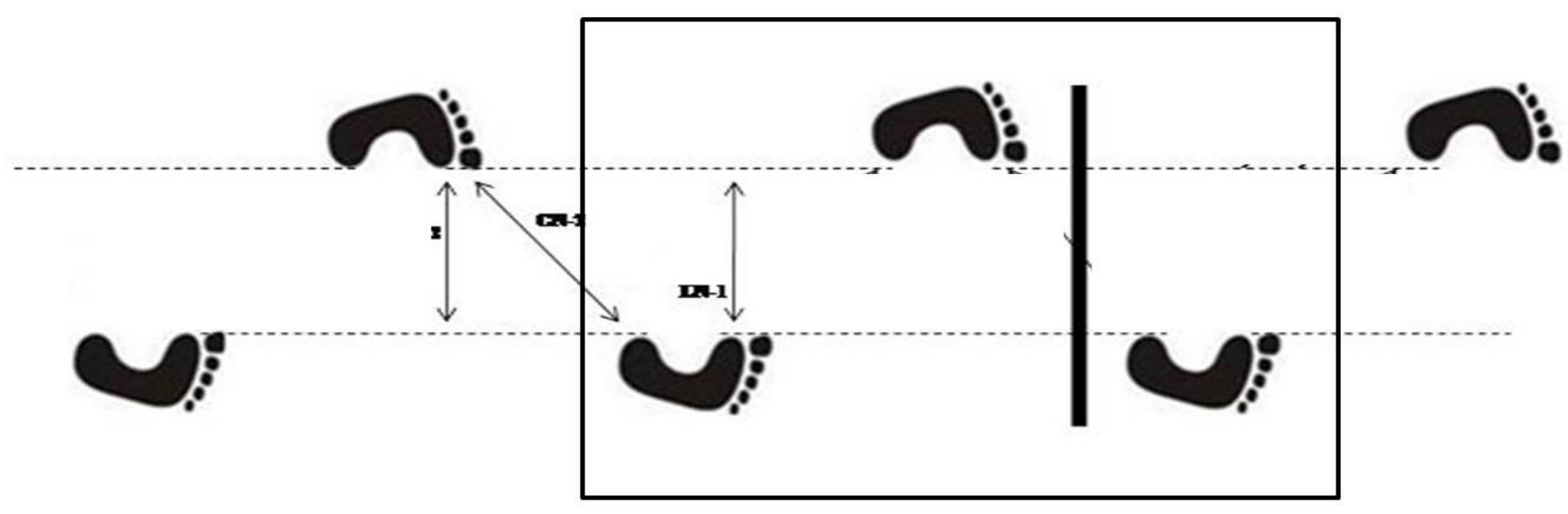

Figure 1. Top view of the stride analyzed. 
Spatial and temporal parameters were statistically analyzed using SPSS 15.0 for Windows ${ }^{\circledR}$ software. The Shapiro-Wilk and Levene tests were employed to check the normal distribution of data and homogeneity of variances, respectively. One-way ANOVA with factor for experimental condition (preferred velocity $\mathrm{x}$ maximum elevation of the feet $\mathrm{x}$ maximum step length $\mathrm{x}$ maximum velocity), with repeated measures, was performed to compare experimental conditions. When univariate analysis revealed a main effect of conditions, Tukey post hoc tests were used to localize the differences between experimental conditions $(p$-adjusted $<.0083)$.

\section{Results}

None of the patients with PD contacted the obstacle during obstacle avoidance in any of the tasks.

The ANOVA showed a main effect of condition for stride length $\left(F_{3,51}=11.68, p<.001\right)$, stride duration $\left(F_{3,51}=38.86, p<\right.$ $.001)$, stride velocity $\left(F_{3,51}=47.83, p<.001\right)$ and double support duration $\left(F_{3,51}=7.31, p<.001\right)$ (Table 2$)$. The post hoc test indicated greater stride length for the maximum velocity and maximum step conditions compared to the preferred velocity condition and the maximum step condition compared to the maximum elevation condition. Moreover, post hoc indicated that the maximum step, maximum elevation and preferred velocity conditions presented higher stride duration and slower stride velocity than the maximum velocity condition and the maximum step condition showed greater stride velocity than the preferred velocity and maximum elevation conditions. For the double support duration, the preferred velocity, maximum elevation and maximum step conditions showed higher values than the maximum velocity condition.

For the horizontal and vertical distance from foot to obstacle (Table 2), the ANOVA also indicated a main effect for conditions of all parameters: horizontal distance from the foot to the obstacle before and after obstacle crossing for the leading limb $\left(F_{3,51}=11.87, p<.001\right.$ and $F_{3,51}=10.47, p<.001$, respectively); horizontal distance from the foot to the obstacle before the crossing for the trailing $\operatorname{limb}\left(F_{3,51}=7.69, p<.001\right)$; vertical distance from the foot to the obstacle during the crossing for the leading $\operatorname{limb}\left(F_{3,51}=9.81, p<.001\right)$ and trailing $\operatorname{limb}\left(F_{3,51}=26.88\right.$, $p<.001)$. For the leading limb, the post hoc indicated greater horizontal distance from the foot to the obstacle before and after obstacle crossing in the maximum velocity and maximum step conditions in comparison to the preferred velocity condition. In addition, the maximum step condition showed greater horizontal distance from the foot to the obstacle before obstacle crossing compared to the maximum elevation condition. Furthermore, for vertical distance from the foot to the obstacle, the maximum elevation condition showed greater distance compared to the preferred velocity, maximum velocity and maximum step conditions, and the maximum step condition showed greater distance than the preferred velocity condition. Regarding the trailing limb, the horizontal distance from foot to obstacle before obstacle crossing in the maximum step condition was greater than the maximum elevation condition. Finally, the post hoc indicated that the maximum elevation condition showed greater vertical distance from the foot to the obstacle compared to the preferred velocity condition

Table 2. Means and standard deviations of spatial-temporal parameters for each experimental condition. HDFO: horizontal distance from the foot to the obstacle; VDFO: vertical distance from the foot to the obstacle; LL: leading limb; TL: trailing limb. PV: Preferred velocity to cross the obstacle; MV: Maximum velocity to cross the obstacle; MS: Maximum step length to cross the obstacle; ME: Maximum elevation of the feet to cross the obstacle.

\begin{tabular}{|c|c|c|c|c|c|c|c|c|c|c|}
\hline & PV & MV & MS & ME & PV $x$ MV & PV $x$ MS & PV $\times$ ME & MV $x$ MS & MVx ME & MS $\times$ ME \\
\hline $\begin{array}{l}\text { Stride length } \\
(\mathrm{cm})\end{array}$ & $106.73 \pm 11.43$ & $119.56 \pm 12.16$ & $122.88 \pm 15.68$ & $108.77 \pm 14.24$ & .001 & .001 & .99 & .99 & .08 & .004 \\
\hline $\begin{array}{l}\text { Stride } \\
\text { duration (s) }\end{array}$ & $1.13 \pm 0.07$ & $0.88 \pm 0.05$ & $1.10 \pm 0.12$ & $1.18 \pm 0.19$ & .001 & .44 & .02 & .001 & .001 & .07 \\
\hline $\begin{array}{l}\text { Stride velocity } \\
(\mathrm{cm} / \mathrm{s})\end{array}$ & $94.45 \pm 15.93$ & $135.86 \pm 17.08$ & $111.70 \pm 17.87$ & $92.17 \pm 19.14$ & .001 & .001 & .60 & .001 & .001 & .001 \\
\hline $\begin{array}{l}\text { Double } \\
\text { support } \\
\text { duration (\%) }\end{array}$ & $27.29 \pm 2.62$ & $24.71 \pm 3.92$ & $27.54 \pm 4.09$ & $30.01 \pm 5.25$ & .001 & 0.99 & .03 & .001 & .001 & .07 \\
\hline $\begin{array}{l}\text { HDFO before } \\
\text { crossing - LL } \\
(\mathrm{cm})\end{array}$ & $74.73 \pm 8.55$ & $82.93 \pm 11.25$ & $85.04 \pm 11.36$ & $76.66 \pm 12.53$ & .001 & .001 & .99 & .99 & .11 & .004 \\
\hline $\begin{array}{l}\text { HDFO after } \\
\text { crossing - LL } \\
(\mathrm{cm})\end{array}$ & $19.66 \pm 4.86$ & $23.78 \pm 4.64$ & $27.48 \pm 9.12$ & $20.64 \pm 6.54$ & .008 & .002 & .99 & .52 & .01 & .01 \\
\hline $\begin{array}{l}\text { VDFO - LL } \\
(\mathrm{cm})\end{array}$ & $11.29 \pm 4.03$ & $12.52 \pm 6.46$ & $14.18 \pm 5.11$ & $20.52 \pm 7.53$ & .99 & .008 & .001 & .35 & .001 & .001 \\
\hline $\begin{array}{l}\text { HDFO before } \\
\text { crossing - TL } \\
(\mathrm{cm})\end{array}$ & $17.24 \pm 4.84$ & $16.25 \pm 7.51$ & $21.71 \pm 5.34$ & $16.93 \pm 4.91$ & .99 & .02 & .99 & .01 & .99 & .004 \\
\hline $\begin{array}{l}\text { VDFO - TL } \\
(\mathrm{cm})\end{array}$ & $16.58 \pm 4.48$ & $18.83 \pm 6.75$ & $19.72 \pm 6.94$ & $23.36 \pm 7.23$ & .22 & .03 & .002 & .99 & .08 & .05 \\
\hline
\end{tabular}




\section{Discussion}

This study investigated whether patients with PD are able to adapt their walking pattern according to restrictions imposed by task instructions during obstacle crossing. The findings confirmed the study hypothesis, indicating that PD patients are able to adapt their walking pattern according to instructions. For example, when the patients with PD were instructed to elevate their foot as much as possible to avoid the obstacle, they increased the margin of safety (toe clearance) from the foot to the obstacle (vertical distance from the foot to the obstacle). Therefore, patients with PD were able to adapt their walking pattern, overcoming the main limitations of the disease (hypometria and bradykinesia). The modulations were directly related to the instructions provided to patients with PD before performing each task, which seems to indicate that attentional cues can influence and benefit strategies during obstacle crossing.

The instructions apparently increased the attention levels of the patients to the task, which could have changed the automatic control (subcortical) of gait to a control directed to the objective (cortical). Thus, the cortex may have assumed the main role, reducing the action of the neural circuits compromised by PD (Beeler et al., 2013; Vitório et al., 2014b). In addition, it is possible to suggest that the strategies used after the instructions were safer for the obstacle crossing than self-selected walking, decreasing the chance of obstacle stumbling.

Patients with PD seem to have the capacity to overcome the motor deficits of the disease during obstacle crossing. PD causes the signals/symptoms of hypokinesia, bradykinesia and muscular rigidity, which affect the locomotion of patients, for example decreasing gait velocity, step length and range of movement, in environments both with and without an obstacle (Dias et al., 2005; Fernández-del Olmo et al., 2004; Goulart et al., 2004; Morris \& Iansek, 1996; Reisis, 2004; Teixeira \& Alouche, 2007). Until now, interpretation of the literature as to whether these motor limitations could be overcome or modulated by this population has been difficult. Based on our results, we suggest that patients with PD can adapt their obstacle crossing parameters, using a safer strategy for crossing the obstacle. These adjustments seem to indicate that the effects of $\mathrm{PD}$ are not able to block modulations for a safe strategy during obstacle crossing. However, the question remaining after this study is why patients with PD do not use this safe strategy in trials performed at their self-selected pattern.

From the findings of the study, we suggest an intervention that incorporates attentional cues for the population with PD. Attentional tips could help patients with PD to increase walking velocity and stride length of their self-selected walking pace, which is performed daily. Patients with PD were shown to have the capacity to adapt their walking in opposition to the effects of $\mathrm{PD}$ and improve their strategies for crossing obstacles, possibly reducing the number of falls.

There are some limitations to this study despite its important findings. First, it is the lack of a control group to compare the effects of instructions on healthy elderly individuals. Second, the sample was restricted to patients with mild-moderate motor impairment. However, the aim of this study was to verify whether patients with PD are able to adjust their motor behavior according to restrictions imposed by the task instructions given, which was little affect for this restriction. We recommend that future studies include patients with severe motor impairment to analyze the effects of these instructions in this group of patients and control group to distingue the effects of aging and PD in the motor behavior.

\section{Conclusion}

Patients with PD are able to adjust walking during obstacle crossing according to instructions given to them. The specific instructions possibly directed more attention to the task execution, changing the control of the movement. After determining that patients with PD are able to modulate the crossing of obstacles, we suggest that future studies investigate the effects of motor interventions in order to incorporate a safe strategy during obstacle crossing. Furthermore, we suggest the inclusion of a control group (matched healthy individuals) for further clarification of the deficits generated by the disease.

\section{References}

Adkin, A.L., Bloem, B.R., \& Allum, J.H.J. (2005). Trunk sway measurements during stance and gait tasks in Parkinson's disease. Gait \&Posture, 22, 240-249.

Azulay, J.P., Mesure, S., Amblard, B., Blin, O., Sangla, I. \& Pouget, J. (1999).Visual control of locomotion in Parkinson's disease. Brain: a journal of neurology, 122, 111-120.

Balash, Y., Peretz, C., Leibovich, G., Herman, T., Hausdorff, J.M., \& Giladi, N. (2005). Falls in outpatients with Parkinson's disease: frequency, impact and identifying factors. Journal of Neurology, 252, 310-1315,

Barbosa, M.T., Caramelli, P., Maia, D.P., Cunningham, M.C., Guerra, H.L., Lima-Costa, M.F., \& Cardoso, F. (2006). Parkinsonism and Parkinson's disease in the elderly: A community-based survey in Brazil (the Bambuí Study). Movement Disorders, 21, 800-808.

Beeler, J.A., Petzinger, G., \& Jakowec, M.W. (2013). The enemy within: propagation of aberrant corticostriatal learning to cortical function in Parkinson's disease. Frontiers in Neurology, 4, 134.

Chou, L.S., \& Draganich, L.F. (1998). Placing the trailing foot closer to an obstacle reduces flexion of the hip, knee, and ankle to increase the risk of tripping. Journal of Biomechanics, 31, 685-691.

Dias, N.P., Fraga, D.A., Cacho, E.W.A., \& Oberg, T.D. (2005).Treino de marcha com pistas visuais no paciente com doença de Parkinson (Gait training with visual cues in patients with Parkinson's disease). Fisioterapia em Movimento, 18, 43-51.

Fahn, S., \& Elton, R. (1987). Members of the UPDRS. Development Comitee. The unified Parkinson's disease rating scale. In: Fahn, S., Marsden, C.D., Calne, D.B., \& Goldstein, M. (eds.) Recent Developments in Parkinson's Disease, 2 (pp 153-163), Florham Park NJ: Mcmellam Health Care Information.

Fernández-Del Olmo, M., Arias, P., \& Cudeiro, J. (2004). Facilitación de la actividad motora por estímulos sensoriales en la enfermedad 
de Parkinson.(Facilitation of motor activity by sensory stimuli in Parkinson's disease). Revista de Neurologia, 39, 841-847.

Folstein , M.F., Folstein, S.E., \& McHugh, P.R. (1975). "Mini-Mental State:" A practical method for grading the cognitive state of patients for the clinician. Journal of Psychiatric Research, 12, 189-198.

Galna, B., Murphy, A.T., \& Morris, M.E. (2010). Obstacle crossing in people with Parkinson's disease: Foot clearance and spatiotemporal deficits. Human Movement Science, 29, 843-852.

Goulart, F., Santos, C.C., Teixeira-Salmela, L.F., \& Cardos, F. (2004). Análise do desempenho funcional em pacientes portadores de doença de Parkinson (Analysis of functional performance in patients with Parkinson's disease). Acta Fisiátrica, 11, 12-16.

Hoehn, M.M., \&Yahr, M.D. (1967). Parkinsonism: onset, progression and mortality. Neurology, 17, 427-442.

Latt, M.D., Menz, H.B., Fung. V.S., \& Lord, S.R. (2009). Acceleration patterns of the head and pelvis during gait in older people with Parkinson's disease: a comparison offallers and nonfallers. Journals of Gerontology Series A Biological Sciences and Medical Sciences, 64, 700-706.

Morris, M.E., \& Iansek, R. (1996). Characteristics of motor disturbance in Parkinson's disease and strategies for movement rehabilitation. Human Movement Science, 15, 649-669.

Morris, M.E., Iansek, R., Matyas, T.A., \& Summers, J.J. (2005). Stride length regulation in Parkinson's disease. Normalization strategies and underlying mechanisms. Brain: a journal of neurology, 119, 551-568.

Petzinger, G.M., Fisher, B.E., McEwen, S., Beeler, J.A., Walsh, J.P., \& Jakowec, M.W. (2013). Exercise-enhanced neuroplasticity targeting motor and cognitive circuitry in Parkinson's disease. Lancet Neurology, 12,716-726.

Picelli, A., Camin, M., Tinazzi, M., Vangelista, A., Cosentino, A., Fiaschi, A., \& Smania, N. (2010). Three-dimensional motion analysis of the effects of auditory cueing on gait pattern in patients with Parkinson's disease: a preliminary investigation. Neurological Sciences, 31, 423-430.

Pieruccini-Faria, F., Menuchi, M.R.T.P., Vitório, R., Gobbi, L.T.B., Stella, F., \& Gobbi, S. (2006). Parâmetros cinemáticos da marcha com obstáculos em idosos com doença de Parkinson, com e sem efeito da Levodopa: um estudo piloto (Kinematic parameters of gait with obstacles among elderly patients with Parkinson's disease, with and without the effect of levodopa: a pilot study). Revista Brasileira de Fisioterapia, 10, 243-249.

Redgrave, P., Rodriguez, M., Smith, Y., Rodriguez-Oroz, M.C., Lehericy, S., Bergman, H., ... Obeso, J.A. (2010) Goal-directed and habitual control in the basal ganglia: implications for Parkinson's disease. Nature Review Neurosciences, 11,760-772.

Reisis, T. (2004). Doença de Parkinson: pacientes, familiares e cuidadores (Parkinson's disease: patients, families and caregivers). Porto Alegre: Pallotti.

Spaulding, S.J., Barbeiro, B., Colby, M., Cormack, B., Mick, T., \& Jenkins, M.E. (2013). Cueing and gait improvement among people with Parkinson's disease: a meta-analysis. Archives of physical medicine and rehabilitation, 94, 562-570.

Stegemöller, E.L. (2012). Postural instability and gait impairment during obstacle crossing in Parkinson's Disease. Archives of Physical Medicine and Rehabilitation, 93, 703-709.
Stolze, H., Klebe, S., Zechlin, C., Baecker, C., Friege, L., \& Deuschl, G. (2004). Falls in frequent neurological diseases prevalence, risk factors and aetiology. Journal of Neurology, 251, 79-84.

Teixeira, N.B., \& Alouche, S.R. (2007). O desempenho da dupla tarefa na Doença de Parkinson (The performance of dual tasks in Parkinson's disease). Revista Brasileira de Fisioterapia, 11, 127-132.

Vitório, R., Pieruccini-Faria, F., Stella, F., Gobbi, S., \& Gobbi, L.T.B. (2010). Effects of obstacle height on obstacle crossing in mild Parkinson's disease. Gait \& Posture, 31, 143-46.

Vitório, R., Lirani-Silva, E., Baptista, A.M., Barbieri, F.A., Dos Santos, P.C., Teixeira-Arroyo, C., \& Gobbi, L.T.B. (2014a). Disease severity affects obstacle crossing in people with Parkinson's disease. Gait \& Posture, 40, 266-269.

Vitório, R., Lirani-Silva, E., Pieruccini-Faria, F., Moraes, R.,Gobbi, L.T., \& Almeida Q.J. (2014b). Visual cues and gait improvement in Parkinson's disease: Which piece of information is really important? Neuroscience, 277, 273-280.

\section{Authors' note}

Vinícius Alota Ignácio Pereira, Rodrigo Vitório, Lucas Simieli, Ellen Lirani-Silva, Diego Orcioli-Silva and Lilian Teresa Bucken Gobbi are with the Gait and Posture Studies Laboratory (LEPLO), Department of Physical Education, UniversidadeEstadualPaulista, Rio Claro, Brazil.

Fabio Augusto Barbieri is with Vision and Action Laboratory (LIVIA); Human Movement Research Laboratory (MOVI-LAB), Department of Physical Education, Universidade Estadual Paulista, Bauru, Brazil.

\section{Corresponding author}

Vinicius Alota Ignacio Pereira

Universidade Estadual Paulista - UNESP - IB - Rio Claro

Laboratório de Estudos da Postura e da Locomoção - Departamento de Educação Física

Avenida 24-A, 1515 - Bela Vista-CEP: 13.506-900- Rio Claro/São Paulo/Brasil

Phone: + 5519 3526-4365 Fax: + 5517991576103

e-mail: viniciusalota_dm@hotmail.com

\section{Acknowledgments}

The authors acknowledge all the members of the PROPARKI Group (Physical Activity Program for patients with Parkinson's disease). The authors also thank for the financial support from PROEX.

Manuscript received on December 1, 2014

Manuscript accepted on October 10, 2015

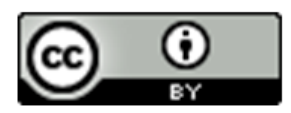

Motriz. The Journal of Physical Education. UNESP. Rio Claro, SP, Brazil - eISSN: 1980-6574 - under a license Creative Commons - Version 3.0 